2 Polmar SH, Stern RC, Schwartz AL, Wetzler GM, Chase PA, Hirshhorn R. Enzyme replacement therapy for adenosine deaminase deficiency and severe combined immunodeficiency. $N$ Engl J Med 1976;295:1337-43.

3 Uberti J, Lightbody JJ, Wolf JW, Anderson JA, Reid RH, Johnson RM. The effect of adenosine on mitogenesis of ADA-deficient lymphocytes. Clin Immunol Immunopathol 1978;10:446-58.

4 Schmalstieg FC, Mills GC, Nelson JA, May LT, Goldman AS, Goldblum RM. Limited effect of erythrocyte and plasma infusions in adenosine deaminase deficiency. $J$ Pediatr 1978;93:597-603.

5 Ziegler JB, Lee CH, Van der Weyden MB, Bagnara AS, Beveridge J. Severe combined immunodeficiency and adenosine deaminase deficiency: failure of enzyme replacement therapy. Arch Dis Child 1980;55:452-7.

- Hirshhorn R, Beratis N, Rosen FS, Parkman R, Stern R, Polmar S. Adenosine deaminase deficiency in a child diagnosed prenatally. Lancet 1975 ;i:73-9.

7 Lee CH, Rozenberg MC, Ziegler JB. Family study on the kindred of an adenosine deaminase deficient child with severe combined immunodeficiency. Aust NZ J Med $1979 ; 9: 530-3$.

8 Daniel A, Lam-Po-Tang PRLC. Prenatal diagnosis in New South Wales: comparative view of the first 1000 cases of chromosome, sex-linked, and metabolic referrals. Med J Aust 1978;ii:352-7.

9 Van der Weyden MB, Bailey L. A micro-method for determining adenosine deaminase and purine nucleotide phosphorylase activity in cells from human peripheral blood. Clin Chim Acta 1978;82:179-84.

10 Chen SH, Scott RR, Swedberg KR. Heterogeneity for adenosine deaminase deficiency: expression of the enzyme in cultured skin fibroblasts and amniotic fluid cells. $\mathrm{Am}$ J Hum Genet 1975;27:46-52.

11 Uitendaal MP, de Bruyn CHMM, Oei TL, Geerts SJ, Hösli P. Fluctuating adenosine deaminase activities in cultured fibroblasts. Biochem Med 1978;20:54-62.

12 Van der Weyden MB, Jack I, Lee CH, Ziegler JB. The establishment of an adenosine deficient lymphoblastoid cell line. Proc Aust Soc Med Res 1977;10:960.

Requests for reprints to Dr J B Ziegler, Prince of Wales Children's Hospital, Randwick, NSW 2031, Australia.

\section{Propionyl coenzyme A carboxylase deficiency presenting as non-ketotic hyperglycinaemia}

SUMMARY A 4-month-old girl presented with myoclonic seizures and an electroencephalogram showing hypsarrhythmia. Hyperglycinuria and a cerebrospinal fluid to plasma glycine ratio of 0.2 suggested the diagnosis of non-ketotic hyperglycinaemia. Propionic acid and methyl citric acid were present in the urine, and propionyl coenzyme A carboxylase was deficient in leucocytes and fibroblasts. The ketotic and non-ketotic hyperglycinaemias cannot be differentiated by CSF: plasma glycine ratios.

Received for publication 9 May 1980
Hyperglycinaemic syndromes in children may assume $\stackrel{\vec{Q}}{?}$ either ketotic or non-ketotic forms. Children with $\Rightarrow$ non-ketotic hyperglycinaemia frequently exhibit $\stackrel{\oplus}{\stackrel{\oplus}{+}}$ myoclonic seizures and an absence of voluntary을 muscle movement. Although few survive the recurrent acute crises in infancy, those who do $\frac{\bar{\rho}}{\vec{D}}$ usually become spastic and profoundly delayed $\stackrel{\Phi}{\mathscr{Q}}$ developmentally. On the other hand, ketotic hyperglycinaemia is clinically characterised by intermittent $\vec{A}$ attacks of ketoacidosis and hyperammonaemia, which may cause vomiting, hypotonia, and lethargy, $\vec{\omega}$ progressing to coma or ultimately death in the neonatal period. ${ }^{1}$ The glycine cleavage system, $\overline{\vec{Q}}$ which converts glycine to serine, is deficient in the cerebral tissue of children with non-ketotic hyper- $\infty$ glycinaemia. Raised brain glycine content and a $N$ cerebrospinal fluid glycine to plasma glycine ratio $\vec{G}$ exceeding 0.03 , in conjunction with clinical differ-o ences, was proposed as a discriminator of non- ketotic from ketotic hyperglycinaemia. ${ }^{2-4}$ Ketotic $\vec{D}$ hyperglycinaemia is the consequence of deficient propionyl coenzyme A carboxylase, methylmalonyl coenzyme A mutase, $\beta$-ketothiolase, or isovaleryl $\varnothing$ coenzyme A dehydrogenase activity, ${ }^{5}$ none of which. appears to affect CSF glycine concentration.

\section{Case report}

A 4-month-old girl was referred to us with the $\frac{\circ}{\otimes}$ classical features of non-ketotic hyperglycinaemia, including excessive glycinuria, myoclonic seizures with a typical hypsarrhythmic electroencephalographic pattern, and a CSF-to-plasma glycine concentration of $0 \cdot 2$. However, despite the absence of ketoacidosis and hyperammonaemia, she was found to have propionic acidaemia and deficient propionyl coenzyme A carboxylase activity. Seizure 3 activity stopped one week after the introduction of ACTH gel therapy and her electroencephalogram reverted to a normal pattern. During the severe 0 illness, plasma glycine was $1154 \mu \mathrm{mol} / 1$ (normal 175 to 296 ), propionate, $153 \mu \mathrm{mol} / 1$ (normal $<3$ ), and caprylate, $100 \mu \mathrm{mol} / 1$ (normal $<3$ ). The cerebrospinal fluid glycine was $213 \mu \mathrm{mol} / 1$ (normal 3- N 10). On gas chromatography/mass spectroscopy $N$ raised concentrations of 3-hydroxypropionate, fuma- N rate, $p$-hydroxyphenylacetate, and methyl citrate ${ }_{0}^{\omega}$ were evident in the urine. Propionyl coenzyme $A$ \% carboxylase activity was deficient in leucocytes and $\stackrel{O}{=}$

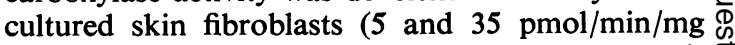
protein, respectively, compared with the correspond- ing normal activities of $349 \pm 51$ and $863 \pm 102$ $\mathrm{pmol} / \mathrm{min} / \mathrm{mg}$ protein). The fibroblast cell line was $\underset{\mathbb{D}}{\stackrel{\mathrm{D}}{\mathrm{N}}}$ assigned to the $p c c B C$ complementation group ${ }^{6}$ and $\stackrel{\stackrel{\rho}{\mathbb{D}}}{\sigma}$ was shown to be unresponsive to biotin. The patient's $\cong$ disorder was managed by dietary protein restriction 
$(1.0 \mathrm{~g}$ protein $/ \mathrm{kg} /$ day). At 9 months of age, atter several weeks of poor feeding, she developed ketoacidosis for the first time. She had another severe episode of acidosis at 11 months of age which was complicated by staphylococcal sepsis and dietary protein deficiency. She has persistently refused to eat, necessitating gavage feeding. Her growth retardation was severe, but has improved during the last year so that now her weight is at the 50th centile for her age, as is her head circumference, while her height is at the 50th centile for a 21month-old. There has been some developmental delay.

\section{Discussion}

Some reported patients have presented clinically with features of ketotic hyperglycinaemia with deficient glycine cleavage activity. One patient with hypotonicity and respiratory depression accompanied by hyperglycinuria, propionic acidaemia, and hyperammonaemia, all suggesting ketotic hyperglycinaemia resulting from PCC deficiency, was found to have normal propionyl coenzyme A carboxylase activity, but deficient glycine cleavage activity. ${ }^{4}$ Several other patients with glycine cleavage deficiency have had hyperglycinaemia, ketoacidosis, hyperammonaemia, propionic acidaemia, and deficient propionyl coenzyme $\mathbf{A}$ carboxylase activity in their fibroblasts. ${ }^{7}$

Our patient, on the other hand, initially manifested findings consistent with non-ketotic hyperglycinaemia but in fact had propionyl coenzyme A carboxylase deficiency. She shows further that neither the initial clinical presentation nor the ratio of CSF to plasma glycine concentrations can be used reliably to differentiate between the types of hyperglycinaemia. Moreover, it is possible that some non-ketotic hyperglycinaemias are reflections of additional genetic heterogeneity in the propionyl CoA carboxylase deficiencies. Alternatively, nonketotic hyperglycinaemia may simply represent a secondary inhibition of the glycine cleavage system by abnormal metabolites which accumulate in propionyl coenzyme A carboxylase deficiency.

Regardless of the aetiology of hyperglycinaemia, the correct diagnosis and differentiation between the types of hyperglycinaemia is therapeutically important. Since most patients with the ketotic forms respond to restricted protein diets and occasionally to pharmacological doses of vitamins, ${ }^{5}$ whereas patients who never develop ketotic forms do not respond to dietary manipulation but may respond to strychnine therapy, ${ }^{8}$ it is essential to exclude the various ketotic hyperglycinaemic enzyme deficiencies by examination of the urine and plasma for organic acid metabolites or, more definitively, by measurement of enzyme activity directly in the tissues of affected subjects.

DAVID J HARRIS, RichaRd M THOMPSON, BARRY WOLF, AND BOB I-Y YANG The Children's Mercy Hospital and

The University of Missouri, Kansas City; Pediatric MetabolismandGenetics, Indiana University; Department of Human Genetics, Medical College of Virginia; and Department of Chemistry, The University of Missouri, Kansas City, USA

\section{References}

1 Nyhan WL. Nonketotic hyperglycinemia. In: Stanbury JB, Wyngaarden JB, Fredrickson DS, eds. The metabolic basis of inherited disease. 4th ed. New York: McGrawHill, 1978:518-27.

2 Scriver CR, White A, Sprague W, Harwood S. PlasmaCSF glycine ratio in normal and nonketotic hyperglycinemia subjects. $N$ Engl J Med 1975;293:778.

3 Farriaux JP, Morel P, Hommes FA. Nonketotic hyperglycinemia with increased propionic acid excretion and hyperammonemia. N Engl J Med 1976;294:558.

${ }^{4}$ Perry TL, Urquhart N, MacLean J, et al. Nonketotic hyperglycinemia: glycine accumulation due to absence of glycine cleavage in brain. $N$ Engl J Med 1975;292:1269-73.

5 Rosenberg LE. Disorders of propionate, methylmalonate and cobalmin metabolism. In: Stanbury JB, Wyngaarden JB, Fredrickson DS, ed. The metabolic basis of inherited disease. 4th ed. New York: McGraw-Hill, 1978:411-29.

6 Wolf B, Hsia YE, Rosenberg LE. Biochemical differences between mutant propionyl-CoA carboxylases from two complementation groups. Am J Hum Genet 1978;30: 455-64.

7 Shafai T, Sweetman L, Weyler W, Goodman SI, Fennessey PV, Nyhan WL. Propionic acidemia with severe hyperammonemia and defective glycine metabolism. $J$ Pediatr 1978 ;92:84-6.

8 Arneson D, Ch'ien LT, Chance P, Wilroy RS. Strychnine therapy in nonketotic hyperglycinemia. Pediatrics 1979; 63:369-73.

Requests for reprints to Dr David J Harris, The Children's Mercy Hospital, 24th at Gillham Road, Kansas City, Missouri 64108, USA. 